\title{
Auricularia polytricha restores altered reproductive parameters in streptozotocin- induced diabetic Wistar rat
}

\author{
Cyril Abang Agbor ${ }^{1 *} \mathbb{D}$, Godson Emeka Anyanwu² and Sule John Audu
}

\begin{abstract}
Background: Local Nigerian men use Auricularia polytricha (wood ear mushroom) growing in farm lands and dead woods to manage sexual dysfunction and this practice has been going on for ages without supporting evidence from scientific experiments. This study was to investigate the ameliorative effect of ethanolic extract of Auricularia polytricha on male sex hormones (FSH, LH, and testosterone), sperm parameters (sperm count, sperm motility, and morphology), and histopathological examination of testis using Streptozotocin (STZ)-induced diabetic rats as a model.

Methods: The experiment included five groups of adult male Wistar rat, group A (normal control, treated with normal saline), group B (diabetic control treated with $65 \mathrm{mg} / \mathrm{kg} . b w$ of STZ), groups C, D, and E (treated with 250 mg/kg.bw, 500 mg/kg.bw, 1000 mg/kg.bw A. polytricha after inducing diabetics). At termination, homogenate was prepared for semen analysis using improved Neubauer's hemocytometer, serum samples were used for hormonal assay with ELISA (enzyme-linked immune sorbent assay) kit and light microscope was used for histopathological examination.
\end{abstract}

Results: Results revealed significant $(p<0.05)$ reduction in sperm count and motility in group B when compared to normal control, values in group $C$ were not statistically significant $(p>0.05)$ when compared to diabetic control. However, groups D and E recorded sperm count and sperm motility that were significantly $(p<0.05)$ increased when compared to the diabetic control (group B). Morphological defects in diabetic control rats were significantly $(p<0.05)$ higher when compared to normal control but there was no statistical significance in group $C$ when compared to the diabetic control, meanwhile values of sperm morphological defects in groups $\mathrm{D}$ and $\mathrm{E}$ were significantly $(p<0.05)$ lower when compared to the diabetic control group. All gonadotropic hormones considered in this research were remarkably lower at $p<0.05$ when compared to normal control. However, these values were significantly higher in groups D and E when compared to diabetic control. Structural alterations in cytoarchitecture of testes as a result of sustained hyperglycemia were reversed in a dose dependent manner following $A$. polytricha administration.

Conclusion: Alterations in sperm parameters, gonadotropic hormones, and histology of testes caused by diabetes were regulated and reversed following administration of graded doses of A. polytricha. This reversal may be attributed to essential phytochemical and therapeutic constituents in A. polytricha which can be found useful in prevention and treatment of diabetes induced testicular dysfunction.

Keywords: Auricularia polytricha, Diabetes, Sex hormones, Sperm parameters, Testes

\footnotetext{
* Correspondence: agbor_cyril@yahoo.com

'Department of Anatomy, College of Medicine, University of Calabar, Calabar, Nigeria

Full list of author information is available at the end of the article
} 


\section{Introduction}

Prevalence of diabetes in sub-saharan Africa has been projected to rise from 7.1 million in 2000 to 18.6 million in 2030 (Saleh, Agarwal, Kandirali, \& Sharma, 2002). According to reports, approximately $50 \%$ of diabetic men will suffer from reproductive dysfunction within five years of the diagnosis (Saumya \& Basha, 2017). Given the alarming prevalence of type II diabetes mellitus (DM) even among youths in the last few decades now drifting towards onset ages of 25-35 years due to urbanization, sedentary life style, dietary, and other factors associated with it.

Studies in diabetic animal model have demonstrated an impairment of sperm quality and fecundity, structural defect, and significantly lower motility of sperm cells (Baccetti et al., 2002), lower ability to penetrate zona free hamster eggs, detrimental effects on endocrine control of spermatogenesis and impairment of erection and ejaculation (Beckam, Goldfire, \& Gordon, 2001), progressive genotoxicity, and so on.

The gradual shift to herbal therapy with its attendant increasing acceptance, even among the elite confirm the claim that herbal remedies can provide cure for several diseases, including infertility in men. A large number of plant and animal products have been tested for possible fertility regulatory properties (Anthony, Oladipo, Adedoyin, \& Tajudin, 2006).

Auricularia Polytricha (wood ear mushroom) grown in farms and death woods for culinary and medical purposes has been found to have numerous medicinal properties. It belongs to the family Auriculariacaea and has been reported to have antioxidant property (Bhatia, Sharma, Pathania, \& Khauduri, 2010). Immunomodulatory activity (Mau, Chao, \& Wu, 2001), anti-tumor activity (Sun, Liu, \& Kennedy, 2010), anti-dementia properties (Bannett et al., 2003), and hypocholesterolemic effect (Zhao et al., 2015).

A. polytricha has been used locally by the Ejagham speaking people in Cross River State of Nigeria as an aphrodisiac agent in management and treatment of sexual dysfunction in men. This has been going on without the corresponding clinical trials and acceptable scientific experimentation to give credence to this age-long practice. The aim of this study is, therefore, to investigate the effect of graded doses of ethanolic extract of $A$. polytricha on some reproductive parameters (sperm quality, sex hormones levels, and histological examination of testis) in streptozotocin-induced diabetic animal model.

\section{Materials and methods Preparation of extract}

Auricularia polytricha was be obtained from Etomi central market located in Etung Local Government Area of Cross River State and taken to the Department of
Biological Sciences, University of Nigeria for identification. The mushroom was dried at room temperature, powdered and subjected to crude extraction with ethanol. Modified method was used for extraction. Two hundred grams of $A$. polytricha was soaked in $1000 \mathrm{ml}$ of ethanol, labeled, and covered for $72 \mathrm{~h}$, after which a clean filter paper (Whatman No. 1) was used to filter extracts. The filtrate was evaporated to dryness at 40 ${ }^{\circ} \mathrm{C}$ in a vacuum using a rotatory evaporator. The extracts was weighed and kept at $4{ }^{\circ} \mathrm{C}$ in refrigerator until further use.

\section{Experimental animals}

Twenty five (25) adult male Wistar rats with average weight of $150 \mathrm{~g}$ were used for this research. The rats were kept in clean cages and divided into five groups designated A, B, C, D, and E with five rats in each group. The rats were allowed to acclimatize for two weeks in animal house, Department of Anatomy, Faculty of Basic Medical Sciences, University of Nigeria, Enugu Campus, and allowed unrestricted access to commercially available chow (livestock feed) and water.

\section{Experimental design (Table 1)}

\section{Induction of hyperglycemia}

After fasting for $12 \mathrm{~h}$, hyperglycemia was induced by administering streptozotocin (STZ) intraperitoneally reconstituted in $0.5 \mathrm{M}$ sodium citrate and administered at a dose of $65 \mathrm{mg} / \mathrm{kg}$.bw (Ugochukwu \& Babady, 2003).

\section{Confirmation of diabetes}

Diabetes was confirmed three days after administration of STZ using Accu-Check glucometer (Roche diagnostic, Germany) with blood samples obtained from tails of Wistar rats. Blood glucose levels were checked before and after induction to ascertain hyperglycemic state.

\section{Administration of extract}

Diabetes was induced and sustained for 2 weeks (14 days) after which administration of $A$. polytricha commenced by oral gastric intubation on the fifteenth and lasted for another 3 weeks (21 days). The experimental protocol was maintained for a total of 5 weeks (35 days).

\section{Termination of experiment and collection of samples for analysis}

At termination, the animals were sacrificed with the testes removed and plotted with filter paper. Both right and left testes were then suspended in Bouins fluid for fixation, preparatory to histological processing. The sperm was collected by mincing from caudal epididymis with anatomical scissors into a glass beaker. Nineteen drops of diluting solution was added to dilute the semen in a 
Table 1 Experimental animals grouping and treatment

\begin{tabular}{lllll}
\hline Group & Designation & Number of animals & Treatment & Dose \\
\hline A & Normal control & 5 & Distilled water & $3 \mathrm{ml}$ \\
B & Diabetic control & 5 & Streptozotocin (STZ) & $65 \mathrm{mg} / \mathrm{kg} . \mathrm{bw}$ \\
C & Low dose & 5 & STZ + A. polytricha & $250 \mathrm{mg} / \mathrm{kg} . \mathrm{bw}$ \\
D & Mid dose & 5 & STZ + A. polytricha & $500 \mathrm{mg} / \mathrm{kg} . \mathrm{bw}$ \\
E & High dose & 5 & STZ + A. polytricha & $1000 \mathrm{mg} / \mathrm{kg} . \mathrm{bw}$ \\
\hline
\end{tabular}

proportion of 1:20. A sample from this homogenate was used for semen analysis.

\section{Determination of sperm count}

Sperm count was done using improved Neubauer's hemocytometer

\section{Determination of sperm motility}

Motility estimates was performed from three fields in each sample and the mean of the three estimates used as the final motility. Sperm motility will be determined as follows:

a) No progressive motility (grade 1+): spermatozoa swinging the tail with no resultant movement.

b) Sluggish motility (grade 2+): spermatozoa moving aimlessly with slow forward progression.

c) Moderate progressive motility (grade $3+$ ): spermatozoa moving at moderate speed with forward progression.

d) Rapid progressive motility (grade 4+): spermatozoa moving at high speed with straight forward progression.

\section{Examination of sperm morphology}

The homogenate was smeared on a clean slide and viewed under microscope at $\times 400$ magnification to assess sperm morphological abnormalities. (Navodita \& Varma, 2014).

\section{Hormonal assay}

Blood samples for hormonal assay were collected by cardiac puncture and allowed to clot, centrifuged to obtain sera which was stored for $24 \mathrm{~h}$ in the refrigerator. ELISA (enzyme-linked immune sorbent assay) kit was used to evaluate levels of follicle stimulating hormone (FSH), leutinizing hormone (LH), and testosterone.

\section{Histological examination}

Tissues were sectioned at $5 \mu$ using microtome. Routine hematoxylin and eosin technique was used for staining (Drury \& Washington, 1973). Stained sections of testes were observed under light microscope (Olympus, model CX23) and photographed at $\times 100$ and $\times 400$ magnification.

\section{Statistical analysis}

Quantitative data from this research was recoded and tabularized. Statistical significance of the differences between the groups was determined using one way analysis of variance (ANOVA) using SPSS (Version 20) statistical analysis program. $p<0.05$ will be considered significant.

\section{Results}

Diabetic control animals (group B) recorded the least values of sperm count $(11.17+0.23$ million $/ \mathrm{ml})$ and sperm motility (29\%), and these values were significantly $(p<0.05)$ lower when compared to group A (sperm count $27.40 \pm 0.83$ million $/ \mathrm{ml}$ and motility $86 \pm 0.66 \%)$,

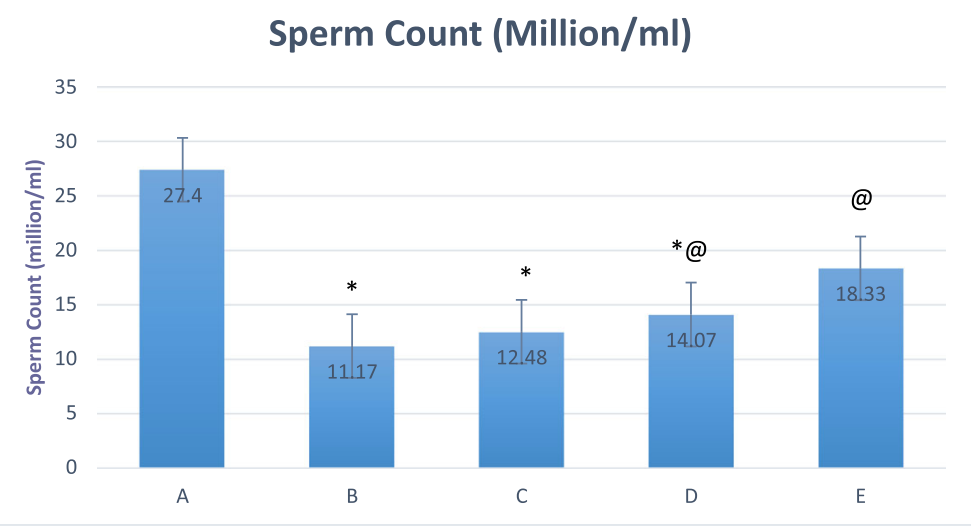

Fig. 1 Comparison of sperm count in the different experimental groups 


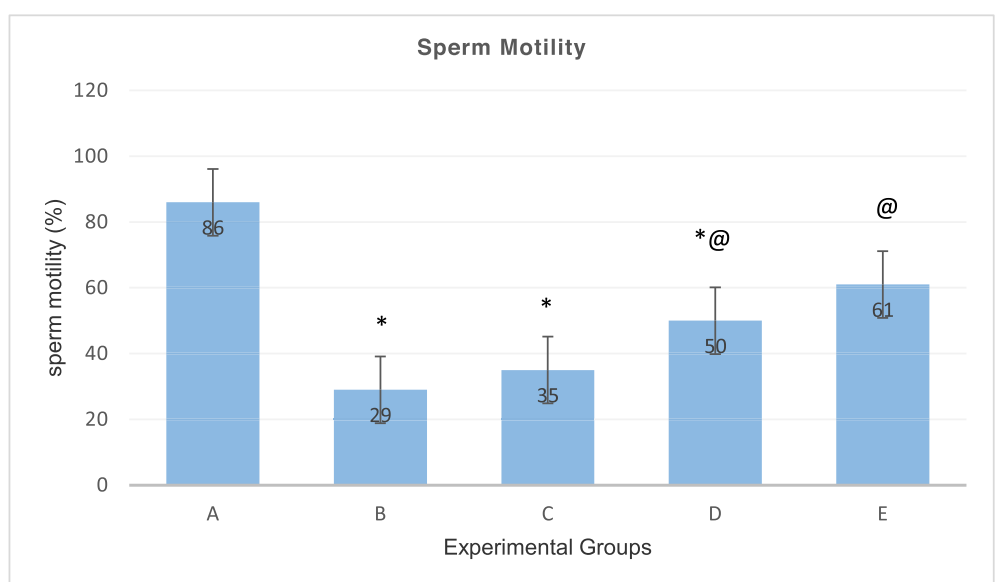

Fig. 2 Comparison of sperm motility in the different experimental groups

but with $A$. polytricha treatment, no significant difference was observed in group $C$ (Diabetic animals placed on $250 \mathrm{mg} / \mathrm{kg}$.bw $A$. polytricha. However, diabetic animals placed on $500 \mathrm{mg} / \mathrm{kg} . \mathrm{bw}$ A. polytricha (group D) and $1000 \mathrm{mg} / \mathrm{kgbw}$ A. polytricha (group E) recorded sperm count and motility that were significantly increased when compared to diabetic control. Sperm morphological defects were significantly increased in group $\mathrm{B}$ when compared to group A while groups D and E recorded remarkably $(p<0.05)$ lower value of sperm morphological defects when compared to diabetic control animals. (Figs. 1, 2, and 3)

Figure 4 reveals that serum levels of FSH and LH were significantly $(p<0.05)$ lower in group B (diabetic control) when compared to group A (normal control). However, values recorded in groups $\mathrm{D}$ and $\mathrm{E}$, diabetic animals placed on 500 and $1000 \mathrm{mg} / \mathrm{kg}$.bw of $A$. polytricha, respectively increased remarkably $(p<0.05)$ when compared to diabetic control. As shown in Fig. 5, a chart comparing the testosterone levels of different experimental groups reveals a decrease in testosterone levels in the diabetic control group $(8.19 \pm 0.61 \mathrm{nmol} / \mathrm{L})$, and this reduction was significantly $(p<0.05)$ lower when compared with normal control group (18.67 \pm 0.49 nmol/L). Groups D (medium dose A. polytricha) and $\mathrm{E}$ (High dose $A$. polytricha) recorded values that were not significantly higher when compared with normal control.

\section{Histopathological examination}

Group A (normal control) revealed that testes had closely packed seminiferous tubules with an intact membrane containing proliferating spermatogonia cells at various stages of maturation. The cells are greater than four layer thick comprising of spermatogia A and B, spermatocytes, spermatids and spermatozoa. There luminal cavity contains flagellae of mature spermatozoa and the separating interstitial matrix contains prominent Leydig cells (Fig. 6a, b).

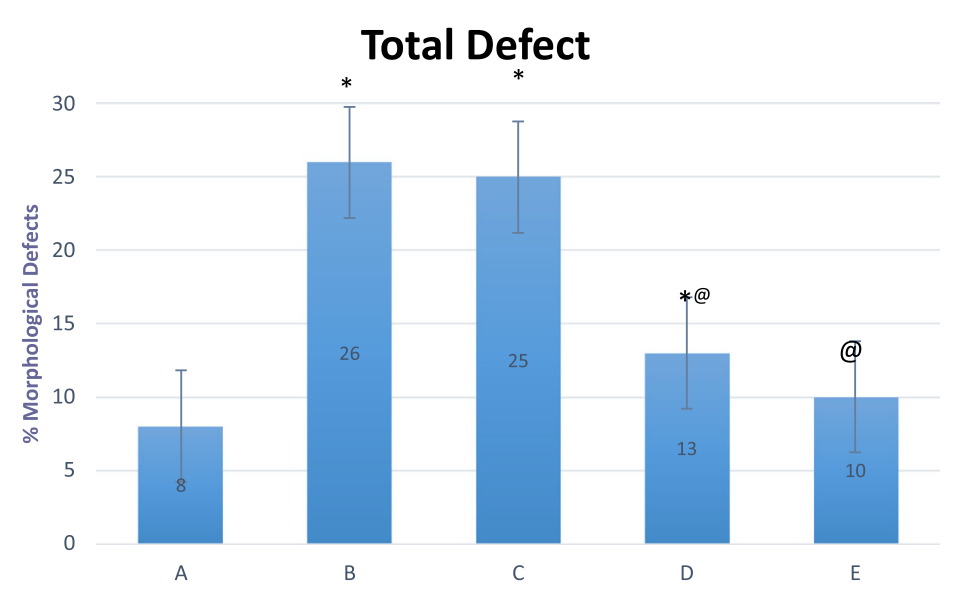

Fig. 3 Comparison of total sperm morphological defect in different experimental groups 


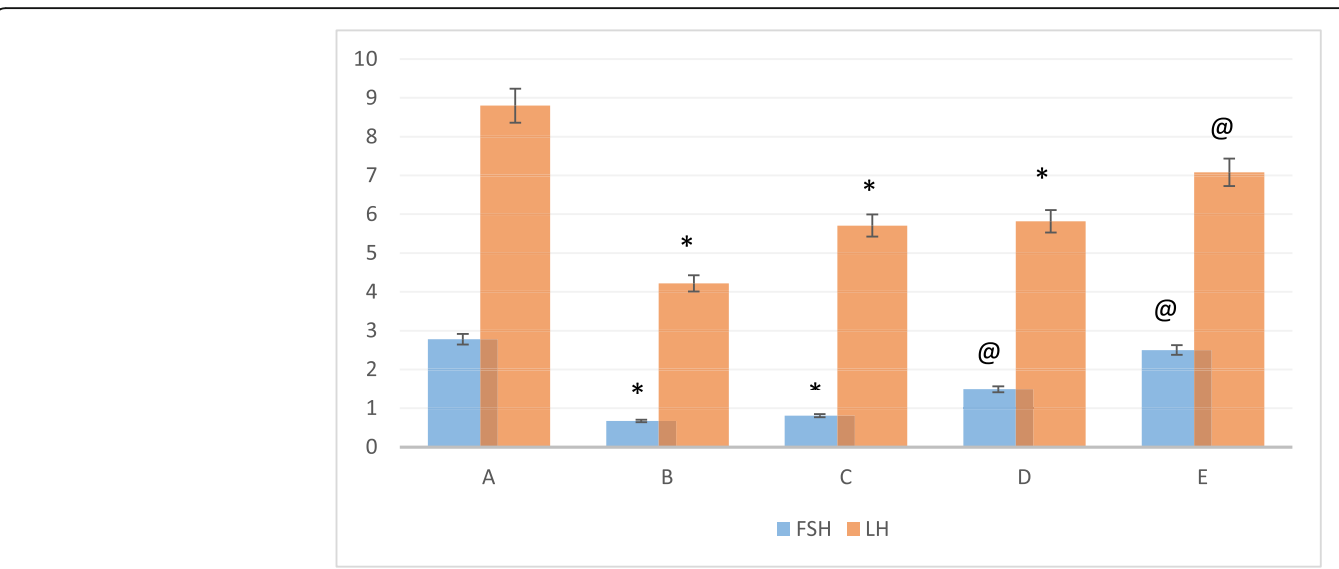

Fig. 4 Comparison of FSH and LH levels in the different experimental groups

Sections of testes from the diabetic control group (group B) showed significant alteration in histological structural pattern in the testes. Irregular-shaped seminiferous tubules with shrunken lumen where observed. The germinal epithelium had scanty differentiating cells arranged in an irregular pattern and tubular lumen contained very few spermatozoa tails. The intervening interstitium was distorted and cells of Leydig were not prominent (Fig. 7a, b).

Photomicrograph of testes in group $\mathrm{C}$ (diabetic animals placed on $250 \mathrm{mg} / \mathrm{kg}$.bw of $A$. polytricha extract) showed irregular and shrunken seminiferous tubules. Fewer spermatogenic cell population on the germinal epithelium and inconsistent cellular associations. The interstitium was irregular and contained Leydig cells (Fig. 8a, b).

The group of diabetic animals treated with $500 \mathrm{mg} / \mathrm{kg}$.bw of $A$. polytricha (group D) showed prominent seminiferous tubules with intact basement membranes and prominent
Leydig cells in the interstitium. A regular cell series of spermatogenic cell series was observed (Fig. 9a, b).

The micro structure of testes in diabetic animals placed on $1000 \mathrm{mg} / \mathrm{kg}$.bw of A. polytricha (group E) revealed prominent seminiferous tubules with intact and undistorted basement membrane. The germinal epithelium had normal and consistent cell associations and tubular lumen with numerous flagella of spermatozoa. The intervening interstitium was regular and contained prominent interstitial cells of Leydig containing blood vessels (Fig. 10a, b).

\section{Discussion}

Testicular dysfunction caused by hyperglycemic conditions may have been responsible for alteration in spermatogenic process, hence the significant $(p<0.05)$ reduction in sperm count observed in diabetic control

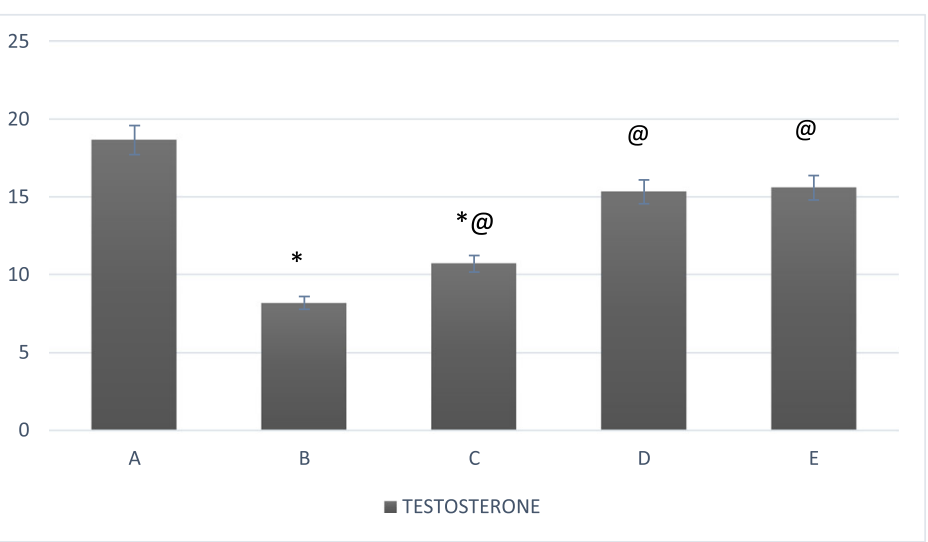

Values are expressed in Mean + SEM. $\mathrm{N}=5$.

$*=$ Values are significantly decreased when compared to normal control at $\mathrm{p}<0.05$.

(a) = Values are significantly increased when compared to diabetic control at $\mathrm{p}<0.05$.

Fig. 5 Comparison of testosterone levels in the different experimental groups 


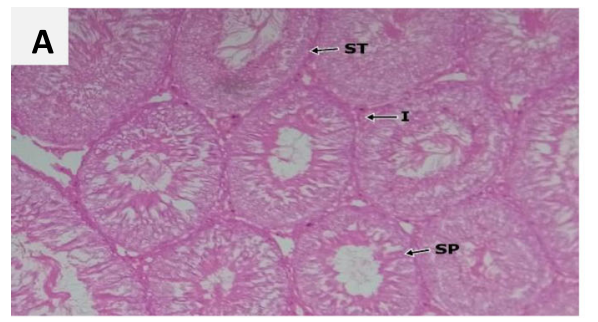

a: X100

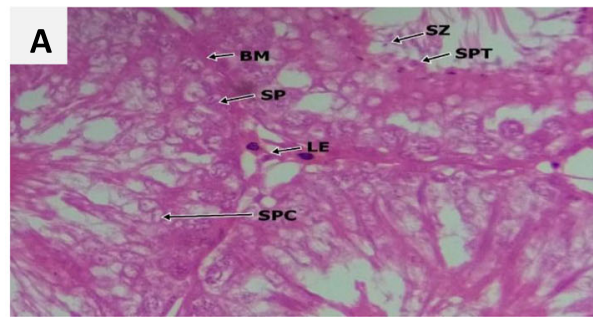

b: $\mathrm{X} 400$

Fig. 6 a Group A (normal control) $\times 100$. b Group A (normal control) $\times 400$

(group B) when compared with normal control. Several experimental evidences have shown that one or more cellular associations in germinal epithelium of testes can be altered in diabetic condition resulting in reduced number of mature spermatozoa (Zhao et al., 2015).

Spermatozoa, unlike other cells, are structurally and functionally unique and are therefore very prone to damage by lipid peroxidation. It has been demonstrated that sperm cells lack the ability to restore alterations caused by increased levels of reactive oxygen specie (ROS) resulting from prolonged hyperglycemia because they do not have the cytoplasmic enzyme system that are required for such reversal. This critical feature makes spermatozoa very susceptible to oxidative insult and may have contributed to low values in sperm count observed in hyperglycemic rats. Krausz, Mills, Rogers, Tan, and Aitken (2015) has also reported so.

According to Halliwell and Gutteridge (2007), reduction in sperm motility has been linked with increase in generation of free radicals in diabetes. From this study, it has been reveals that sperm motility in rats under the influence of STZ-induced diabetes decreased remarkably when compared with normal control. The link between hyperglycemia and sperm motility has been attributed to the series of events that decreases protein phosphorylation resulting in sperm immobilization, which are related to reduced membrane fluidity required for fertilizing capabilities of spermatozoa. This is consistent with findings of Aitken and Krause (2007).
It is also reasonable to suggest that $A$. polytricha extract may have been responsible for restoration and remarkable improvement in sperm parameters when compared to the diabetic control group because of the antioxidant agents in phenolic and flavonoid contents as well as tocopherol and ascorbic acid as found in $A$. polytricha. This observation finds backing from Chen et al. (2011), who reported that A. polytricha is a good exogenous source of antioxidant that can prevent oxidative stress in testes thereby improving fertility outcomes.

Low levels of gonadotropic hormones in group B as shown in this study may have been as a result of sustained hyperglycemia. Findings from Brunning et al. (2000) revealed that diabetes is capable of disrupting activities of the Hypothalamo-pituitary-gonadal axis $(\mathrm{H}-$ P-G axis) resulting in low serum concentration of androgenic hormones, impaired spermatogenesis, and subsequent subfertility. Insulin receptors have been detected in the hypothalamus and play a critical function as a signaling hormone in the central nervous system. Insulin is also a potential signal to the brain on body energy homeostasis, thus lack of insulin in a diabetic condition may have signaled lack of energy supply and knocked out of brain-specific insulin receptors thereby alterations in the hypothalamo-pituitary-gonadal axis, as a consequence, lower levels of FSH and LH. Reduction in levels of plasma testosterone in diabetic control rats may have been linked to low gonadotropic hormones,

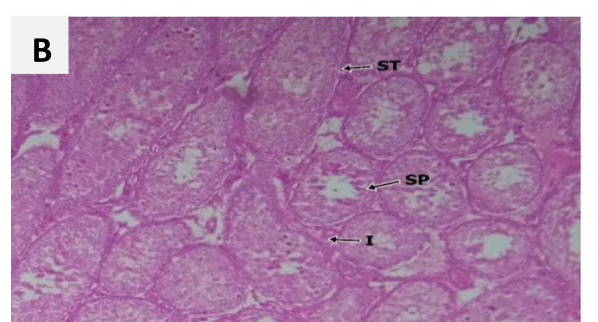

a: X100

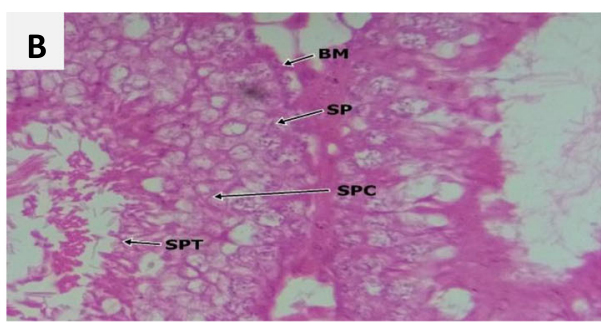

b: $\mathrm{X} 400$

Fig. 7 a Group B (diabetic control) $\times$ 100. b Group B (diabetic control) $\times 400$ 


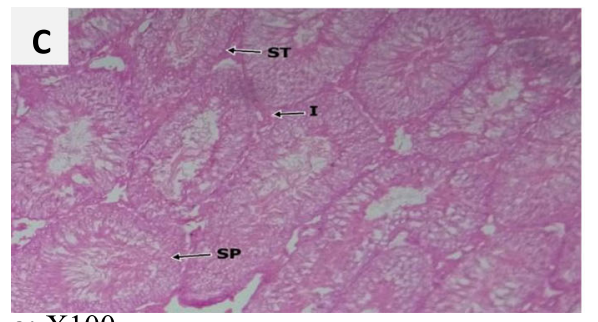

a: X100

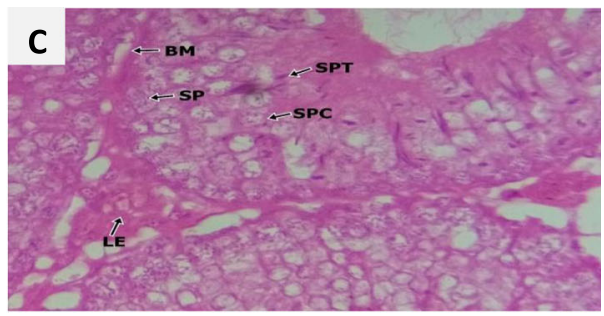

b: $\mathrm{X} 400$

Fig. 8 a Group C (diabetes +250 mg/kg.bw A. polytricha) $\times 100$. b Group C (diabetes +250 mg/kgbw A. polytricha) $\times 400$

especially LH because gonadotropin releasing hormone $(\mathrm{GnRH})$ pulses from the hypothalamus will stimulate the pituitary gland to release FSH and $\mathrm{LH}$ which will in turn act on Sertoli cells and Leydig cells to stimulate spermatogenesis. The absence of stimulatory effect of insulin on Leydig cells may also have been implicated.

However, A. polytricha administration may have improved the values of circulating $\mathrm{LH}, \mathrm{FSH}$, and testosterone levels as was observed in groups $\mathrm{C}, \mathrm{D}$, and $\mathrm{E}$ placed on $250 \mathrm{mg} / \mathrm{kg}$.bw, $500 \mathrm{mg} / \mathrm{kg} . \mathrm{bw}$, and $1000 \mathrm{mg} / \mathrm{kg} . \mathrm{bw}$, respectively. This significant $(p<0.05)$ increase when compared with the diabetic control may be attribute to the fact that $A$. polytricha is capable of raising levels of leptin, an important biomolecule that interacts with insulin in the homeostasis mechanism of the CNS. This finding has the support of Obici, Zhang, Karkanias, and Rossetti (2002) and German, Wisse, Thaler, Oh, and Sarruf (2010) who said that decreased levels of leptin are associated with insulin resistance in type II diabetes.

From this research, histological observation on the testes reveals that testicular histology was significantly altered in diabetic rats when compared to the normal control. Less prominent and shrunken seminiferous tubules with loose basement membrane, scanty interstitium, non-visible Leydig cells, and distorted germinal epithelium were observed in photomicrograph of group $\mathrm{B}$ when compared with normal control (group A). These are indicators of testicular tissue damage. Kowluru, Kanwar, and Kennedy (2007) have confirmed and reported that STZ-induced diabetes is responsible for alteration in histology of testes, reduction, and possible death of germ cells in experimental animals. This observation also finds support in a study by Ahmed (2005) who reported that free radical production during oxidative stress explains the pathophysiology and biological effect of diabetes mellitus especially regarding cellular degeneration, tissue damage, and subsequent complication. Restoration of testicular lesion was seen in groups treated with $A$. polytricha; it is therefore appropriate to suggest that mechanisms other than regulation of hyperglycemia were responsible for improved testicular cytoarchitecture. This improvement may be linked to the antioxidant capacity and lipoprotein lipase activity of $A$. polytricha polysaccharides which are natural antioxidant that could be used as an alternative in resisting oxidation process. Research has shown that the use of synthetic antioxidant may be limited as it showed potential danger in terms of adulteration (Johansen, Rychly, Harris, \& Ergul, 2005). Mushroom and mushroom-derived polysaccharides have been shown to have nutritious and therapeutic properties against metabolic syndrome and may be clinically recommended in management and treatment of diabetes-related reproductive dysfunction.

\section{Conclusion}

Results from this research clearly demonstrates that microstructural alterations in testes of STZ-induced diabetic rat were regulated, reversed, and restored following

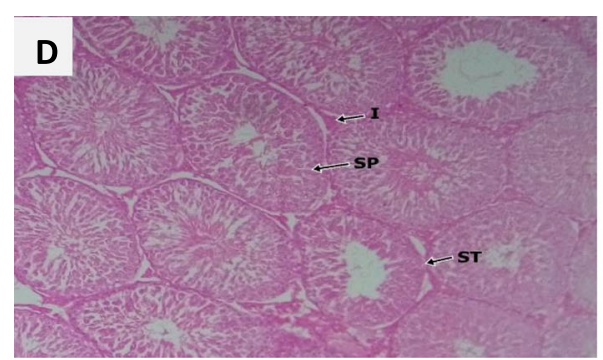

a: $\mathrm{X} 100$

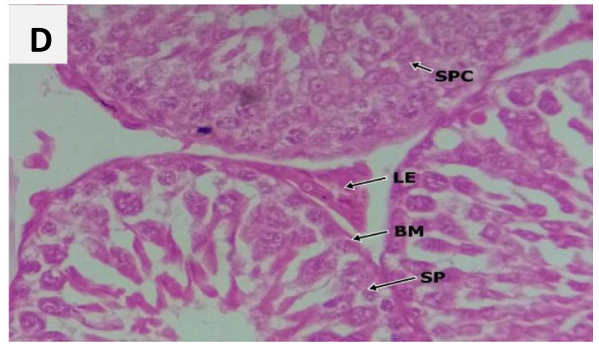

b: $\mathrm{X} 400$

Fig. 9 a Group D (diabetes +500 mg/kg.bw A. polytricha) $\times 100$. b (Diabetes +500 mg/kg.bw A. polytricha) $\times 400$ 


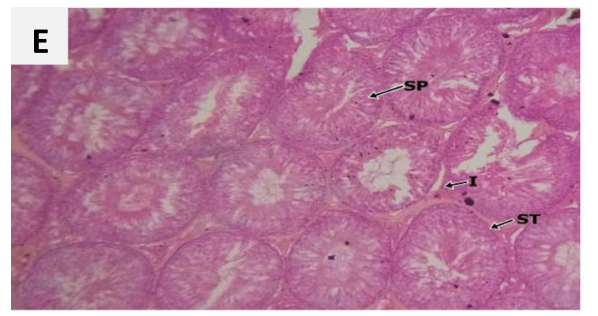

a: $\mathrm{X} 100$

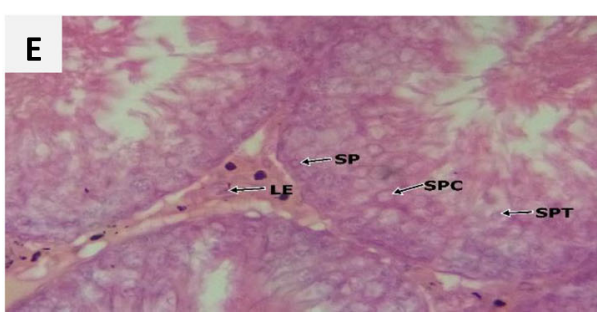

b: $\mathrm{X} 400$

\section{KEY \\ I - Interstitium \\ LE - Leydig cell \\ BM - Basement Membrane \\ $\mathrm{SP}$ - Spermatogonia}

SPC - Spermatocytes

SZ - Spermatozoa

SPT - Spermatid

Fig. 10 a (Diabetes $+1000 \mathrm{mg} / \mathrm{kg} . b w$ A. polytricha) $\times 100$. b (Diabetes $+1000 \mathrm{mg} / \mathrm{kg} . b w$ A. polytricha) $\times 400$

administration of ethanolic extract of $A$. polytricha. This restoration could be attributed to essential phytochemical constituents like polyphenol and flavonoid which may be found useful in prevention and treatment of diabetes induced testicular dysfunction. Reproductive parameters like sperm quality and circulating gonadotropic hormones levels that were altered significantly by sustained hyperglycemia improved in a dose-dependent manner, following 21 days of $A$. polytricha administration.

\section{Acknowledgements}

I acknowledge the technical support from Department of Histopathology, University of Calabar Teaching Hospital, Nigeria and Endocrinology Laboratory in the Department of Biochemistry, University of Calabar Nigeria.

\section{Ethical approval and consent to participate}

Ethical clearance was obtained from the local Animal Use Ethical Committee, Faculty of Basic Medical Sciences, University of Calabar, Nigeria, with number UC/EC/19/243. Guidelines provided by the ethical committee were strictly adhered to.

\section{Authors' contributions}

Authors' contributions to this research are as follows: CAA performed semen analysis, histopathological examination and drafted the manuscript; GAE performed hormonal assay, statistical analysis of sperm parameters and supervised the entire experimental protocol; SJA took part in breeding animals, preparation of Auricularia polytricha extract and administration of extracts. All author(s) read and approved the final manuscript.

\section{Funding}

There was no funding from external sources for this research

\section{Availability of data and materials}

Data sharing is not applicable to this article as no datasets were generated or analyzed during the current study.

\section{Consent for publication}

Not applicable

\section{Competing interests}

All authors in this research are not by any means linked to any funding body and so there was a complete absence competing interest or external influence.

\section{Author details}

${ }^{1}$ Department of Anatomy, College of Medicine, University of Calabar, Calabar, Nigeria. ${ }^{2}$ Department of Anatomy, College of Medicine, University of Nigeria, Enugu, Nigeria.

Received: 10 March 2020 Accepted: 11 May 2020

Published online: 29 May 2020

\section{References}

Ahmed, R. G. (2005). The physiological and biochemical effects of diabetes on the balance between oxidative stress and antioxidant defence system. Medical journal of Islamic world academic science, 15, 31-42.

Aitken, R. J., \& Krause, N. F. (2007). Origins and consequences of DNA damage in male germ cell. Reproductive Biomedicine Online, 14, 727-733.

Anthony, B. O., Oladipo, A. L., Adedoyin, K. L., \& Tajudin, I. A. (2006). Phytochemistry and spermatogenic potential of aqueous extracts of Cissus Populnear. The Science World Journal, 6, 2140-2146 https://doi.org/10.1100/ tsw.2006.343.

Baccetti, B., La Marca, A., Pioboni, P., Capitani, S., Bruni, E., Petraglia, F., \& De Leo, V. (2002). Insulin-dependent diabtes in men is associated with hypothalamopituitary derangement and with impairment of semen quality. Human Reproduction, 17(10), 2673-2677.

Bannett, R. N., Mellon, F. A., Foidl, N., Pratt, J. H., Duport, M. S., Perkins, L., \& Kroon, P. A. (2003). Profiling glucosinolates and phenolics in vegetative and reproductive tissues of the multipurpose tree Moringa oleifera L. Journal of Agricultural and Food Chemistry, 51, 3346-3553.

Beckam J. A., Goldfire A. B., Gordon M. B. (2001) Endothelium - dependent vasodilation impaired by acute hyperglycaemia in human circulation. 103: 1618-1625

Bhatia, D. K., Sharma, A. K., Pathania, P. C., \& Khauduri, N. C. (2010). Antifertility effect of crude extract of Adiantum Lunulatum on Reproductve organs of male wister rats. Int. journal on Biological Forum, 2(2), 88-93.

Brunning, J. C., Gautam, D., Burks, D. J., Gillette, J., Schubert, M., Orban, P. C., \& Kahn, C. R. (2000). Role of brain insulin receptor in control of body weight and reproduction. Science, 289(5487), 2122-2125.

Chen, G., Luo, J.-C., Ji, B.-P., Li, B., Su, W., Xiao, Z.-L., \& Zhang, G.-Z. (2011). Hypocholesterolemic effects of Auricularia polytricha ethanol extract in ICR mice fed a cholesterol-enriched diet. Journal of Food Science and Technology, 48(6), 692-698

Drury, R. A. and Washington E. A. (1973). Carlitons Histological Techniques. 4th ed. Oxford press, London. Pp250.

German, J. P., Wisse, B. E., Thaler, J. P, Oh I. S., Sarruf D. A. (2010). Leptin deficiency causes insulin resistance induced by uncontrolled diabetes. Diabetes, 59(7), 1626-1634. Dio:https://doi.org/10.2337/db09-1918.

Halliwell, B., \& Gutteridge, J. M. (2007). Measuring reactive specie and oxidative damage in vivo and in cell culture: how should you do it and what do the result mean? British Journal of Pharmacology, 142, 231-255. 
Johansen, J. S., Rychly, D. J., Harris, A. K., \& Ergul, A. (2005). Oxidative stress and the use of antioxidant in diabetes: linking basic science to chemical practice. Cardiovascular Diabetology, 4(1), 5.

Kowluru, R. A., Kanwar, M., \& Kennedy, A. (2007). Metabolic memory phenomenon and accumulation of peroxynitrites in retinal capillaries. Journal of Experimental Diabetic Research, 2007, 21976.

Krausz, C., Mills, C., Rogers, S., Tan, S. L., \& Aitken, R. (2015). Stimulation of oxidant generation by human sperm suspensions using phorbol esters and formyl peptides: relationships with motility and fertility in-vitro. Journal of Fertility and Sterility., 62, 599-605.

Mau, J. L., Chao, G. R., \& Wu, K. T. (2001). Antioxidant properties of ethanolic extracts from several ear mushrooms. Journal of Agricultural and Food Chemistry, 49, 5461-5467.

Navodita, P. and Varma, M. C. (2014) Effect of morina leaf powder on testes of Aloxan monohydrate - induced diabetic mice mus musculus. American International Journal of Research in Formal and Applied Sciences: 2328-3785.

Obici, S., Zhang, B. B., Karkanias, G., \& Rossetti, L. (2002). Hypothalamic insulin signaling is required for inhibition of glucose production. Nature Medicine, $8(12), 1376-1382$

Saleh, R. A., Agarwal, A., Kandirali, E., \& Sharma, R. K. (2002). Leukocytospermia is associated with increased reactive oxygen specie production by human spermatozoa. Journal of Fertility and Sterility, 78, 1215-1224.

Saumya, S. M., \& Basha, P. M. (2017). Fluoride exposure aggravates the testicular damage and sperm quality in diabetic mice: protective role of ginseng and banaba. Biological Trace Element Research, 177, 331-344.

Sun, Y. X., Liu, J. C., \& Kennedy, J. F. (2010). Purification, composition analysis and antioxidant activity of different polysaccharide conjugates (APPs) from the fruiting bodies of Auricularia polytricha. Carbohydrate Polymers, 82, 299-304.

Ugochukwu, N. H., \& Babady, N. E. (2003). Antihyperglycaemic effect of aqueous and ethanolic extracts of Gongronema latifolium leaves on glucose and glycogen metabolism in livers of normal and streptozotocin induced diabetic rat. Life Sciences, 73(150), 1925-1938.

Zhao, C., Liao, Z., Wu, X., Liu, Y., Liu, X., Lin, Z., ... Liu, B. (2015). Isolation, purification, and structural features of a polysaccharide from Phellinus linteus and its hypoglycemic effect in alloxan-induced diabetic mice. Journal of Food Science, 79, H1002-H1010.

\section{Publisher's Note}

Springer Nature remains neutral with regard to jurisdictional claims in published maps and institutional affiliations.

\section{Submit your manuscript to a SpringerOpen ${ }^{\circ}$ journal and benefit from:}

- Convenient online submission

- Rigorous peer review

- Open access: articles freely available online

- High visibility within the field

- Retaining the copyright to your article

Submit your next manuscript at $\boldsymbol{\nabla}$ springeropen.com 